\title{
Ten minutes with Hassan Khouli, chair of Department of Critical Care Medicine, Respiratory Institute, Cleveland Clinic
}

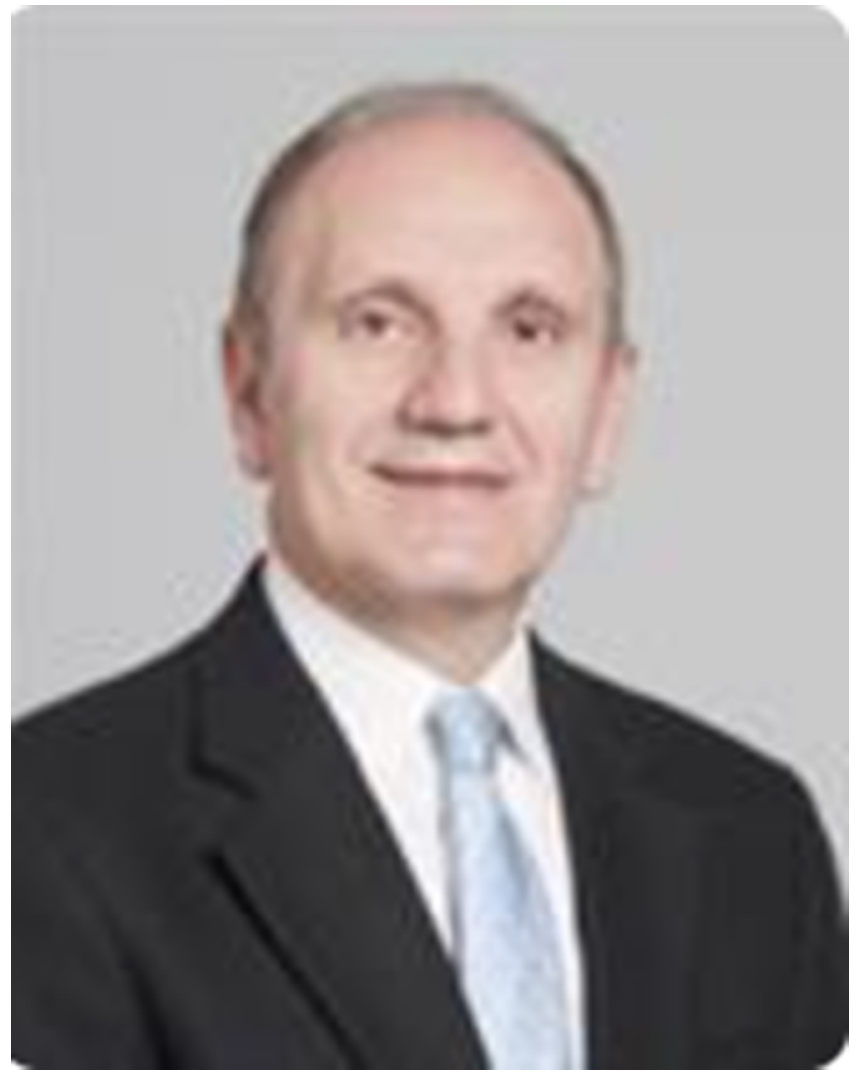

FIRST AND FOREMOST, ARE THERE ANY KEY LEADERSHIP
MESSAGES YOU WANT TO GET OUT TO OUR READERSHIP?

It is important for people to recognise that this is probably the most challenging crisis we have faced in healthcare and possibly the most challenging crisis we may be facing in our lifetime. The global nature of this pandemic, the magnitude of what we are experiencing, the tremendous effects on every segment of our society, and the devastating impacts-not just economic impacts, but social and health impacts that this crisis is having-is an unprecedented scale for us to be mindful of. I think that type of a crisis requires us to all bond together and understand that we need to work together across the Globe and to be proactive. We should not be distracted by shortcomings in someone's behaviour or responsiveness. We need to focus on 'How to collaborate as team of teams' at a hospital, society, a national or international levels. To summarise, we are facing a crisis at a scale we have not seen in recent memory. With collaboration, resilience, and innovation, we will be able to overcome this unprecedented crisis.

\section{TELL US A LITTLE BIT ABOUT YOUR LEADERSHIP ROLE AND HOW IT IS CHANGING AS A RESULT OF THE PANDEMIC?}

$\mathrm{I}$ am at the Cleveland Clinic in Cleveland, Ohio. I chair the Department of Critical Care Medicine. I have been in this role for the past 2 years, after working in New York City for over 20 years. I oversee critical care medicine services across the enterprise in North-eastern Ohio. Several ICUs in our system care for patients with COVID-19-related critical illnesses. We have been

\section{Biography}

Dr Hassan Khouli, MD, is the chair of the Department of Critical Care Medicine in the Respiratory Institute at the Cleveland Clinic. He has over 20 years of experience working in critical care medicine and pulmonary medicine. Dr Khouli has special expertise in the evaluation and management of patients with complex critical illnesses including sepsis and septic shock, ARDS, multiorgan failure and decision-making at the end of life. Dr Khouli leads the Enterprise-Wide Department of Critical Care Medicine at the Cleveland Clinic that oversees 12 adult ICUs at eight hospitals including Main Campus and seven regional hospitals with over 170 ICU beds.

Prior to joining the Cleveland Clinic, Dr Khouli was a professor of Medicine at the Icahn School of Medicine at Mount Sinai in New York, the chief of the Critical Care Division at Mount Sinai St Luke's and Mount Sinai West Hospitals and the chair of Medical Ethics for over 15 years. Dr Khouli was an early leader in the development of simulation training and he founded the Center for Advanced Medical Simulation (CAMS), one of the earliest centres in the USA to be accredited by the Society for Simulation in Healthcare. Dr Khouli has been actively involved in public policy. He has been an invited lecturer regionally, nationally and internationally. He has received several government, private foundation and industry research grants and has authored many peer-reviewed articles, abstracts and book chapters. He has been elected to 'Best Doctor in America' several years.

preparing to face these challenges from an enterprise/systemwide view.

As leaders, we set vision, directions, and priorities for our team and programmes. A serving leader aims to earn the trust of his/or her teams of colleagues. We want to support our teams and their professional and personal growth, delivery of high standards of care for our patients, and to continue to innovate. During the COVID-19 era, we as leaders have been focusing on protecting our vulnerable caregivers and teams from exposure to the COVID-19 virus and supporting their mental health and well-being as one of the most important priorities, while we aim continue to provide the best care for our patients. We have a responsibility to protect our teams, to provide them with the resources, education, and knowledge, and to keep them informed to make decisions that will impact their wellbeing, the well-being of their colleagues and their patients. I find myself often being driven by this priority as a North Star while continuing to balance with providing care for our patients as our mission in healthcare to care for the sickest.

\section{WHAT EVENTS IN YOUR PAST EXPERIENCE ARE MOST INFORMING YOUR LEADERSHIP IN THIS PANDEMIC?}

Having lived in New York City for over 20 years before joining the Cleveland Clinic, I was an ICU director during the 9/11 event in NYC. I was in Manhattan rounding in the ICU on $9 / 11$ when the first airplane hit the Twin Towers. We went through a shock phase and the whole world changed afterward. Leading and managing through the 9/11 event helped me understand and prepare better for the COVID-19 challenges that impact 
our colleagues, teams, and programmes, and how to prepare and plan. The 9/11 catastrophic event was a one-time event. The COVID-19 crisis is ongoing with twists and turns every day.

I led sections and departments in New York City. I managed emergency events during hurricane seasons that hit New York (eg, Hurricane Sandy). I was part of incident command teams and the emergency preparedness planning teams for years. These experiences were very helpful with bird's-eye view of what it takes to prepare our teams during crisis on this scale while maintaining calmness, reassurance, and to lead within the Cleveland Clinic Health System as the enterprise planned and prepared for the COVID-19 crisis. We learn from our prior experiences that inform us on how to face the next challenge to prepare our teams and ourselves as leaders. It is key for leaders to understand how to motivate, energise, and mobilise their teams. Keep your team focused and supported, and inspire them to do important work. Past leadership experiences taught us the importance to work closely with our teams, to lead by example, and motivate our teams to continue to do the right thing during these high stress situations.

\section{WHAT ARE YOU FINDING THE BIGGEST CHALLENGES?}

One of the challenges is the size of the Cleveland Clinic Health System and how to manage across all hospital sites during current challenging times where it is paramount to communicate and integrate our teams. Planning and preparing our teams across eight hospitals with differences in patient populations, disease complexity (eg, main campus vs regional hospitals), and resources has been a challenge and an opportunity. We need most of our ICUs and teams across the health system to be ready to manage critically ill patients with COVID-19. We plan to admit patients throughout our ICUs and prepare our teams across the enterprise. Accomplishing this during the state of social distancing has presented another layer of complexity. We have to balance the desire to 'want to be with my team' and to have a face-to-face conversation, with the importance of compliance with social distancing. We are leveraging other platforms of communication and interactions (virtual communication platform) and becoming more comfortable with these methods of communications to continue to engage with our teams as leaders. We continue to promote social distancing in different spaces including within our ICUs, to protect our caregivers while connecting and communicating with our teams.

\section{ANY PARTICULAR SURPRISES?}

Yes, several pleasant surprises. When faced with a crisis at this scale, you are not sure how your team and your organisation are going to respond. There is real fear, anxiety, and nervousness among many of us. This is natural when we feel our health, our family's health, our friends' health, are in danger. What I observed and experienced is how enthusiastic, energetic, dedicated, and creative the people I work with. They are amazing. They challenge us and motivate us to do better and to think outside the box when facing a challenge at this scale. We are seeing incredible team building and dedication, and a desire to lead and to serve. This is quite remarkable.

I am also impressed by how well organised and efficient the Cleveland Clinic Health System during crisis at this scale. How rapidly and efficiently decisions, processes, protocols, and large operations have been established. We see leaders behave and act with calmness. They have been there. This has been a pleasant and reassuring surprise. Today, a fresh example to share with you. The FDA approved a process for sterilising N95 masks.
The Cleveland Clinic signed up for implementing this process to preserve N95s. A major operation was set up at one of our facilities and started working on this probably earlier than anybody else in the USA. Within few days, almost 8000 N95 masks have been sterilised and are ready to go back to be used by caregivers when needed. This unique example validates the high-efficiency operations at the Cleveland Clinic and is a major advantage during pandemic crisis situation.

I am also impressed by the innovative nature of our teams in preparedness for the COVID-19 pandemic. With transparency and rapid cycle planning and implementation while thinking creatively and a 'can do it' attitude, we set up our ICUs across the health system in a ready and safe state to care for COVID-19 patients and to keep our caregivers safe. Our IV pumps and ventilators are set up outside the rooms to minimise caregivers' exposure. We leveraged our well-organised and integrated teams to plan and implement key practices. We continue to learn and, adjust, adapt, and share best practices across our integrated systems.

\section{ARE YOU SEEING ANY BEHAVIOURS FROM COLLEAGUES THAT ENCOURAGE OR INSPIRE YOU?}

Many examples of inspiring behaviours. Impressive display of responsiveness and teamwork. Colleagues are bonding with high level of engagement. The attitude of wanting to serve is very visible. Our colleagues are working hard and you can easily feel a sense of enjoyment and readiness to 'jump in'. They are brave and not afraid of facing the challenges.

\section{HOW ARE YOU MAINTAINING KINDNESS AND COMPASSION?}

I am calm in nature. We all have our coping mechanisms to deal with stresses at different scales. I find it quite important and helpful to listen. Our colleagues sometimes need to vent. We can hear them and be reassuring. It is important to project a sense of calmness to our teams. When people are reassured and calmer they are more productive. These days I self-reflect more often and stay composed, and be conscious of being empathetic to people around us.

\section{ARE THERE ANY READINGS THAT YOU FIND HELPFUL FOR INSPIRATION AND SUPPORT THAT YOU WOULD RECOMMEND TO OTHERS?}

I probably could read more non-COVID materials. Considering the limited available time now, I've been more impressed in medical and scientific readings. I enjoy reading inspiring stories in newspapers or materials shared by colleagues. I read a recent article about social distancing and how it is impacting a grandmother who is in a major leadership role. Her granddaughter would like to give her a hug but asked to keep a distance. She used this example to acknowledge the challenges social distancing present in our daily lives while she continues to inspire her team to maintain social distancing and safety. We lead by example. The rules apply to everyone when doing the right thing while maintaining kindness and composure. These reading and stories make a difference.

\section{WHAT ARE YOU LOOKING FOR FROM YOUR LEADERS?}

We would like our leaders to continue to have high integrity, transparency, and enthusiasm for creative thinking. Maintaining calmness and leading by example during these challenging times are critical. 


\section{0 minutes with...}

Hassan Khouli, ${ }^{1}$ Amit Nigam (D) 2

${ }^{1}$ Respiratory Institute, Cleveland Clinic, Cleveland, Ohio, USA

${ }^{2}$ Cass Business School, City, University of London, London, UK

Correspondence to

Professor Amit Nigam, Cass Business School, London EC1Y 8TZ, UK; Amit.Nigam.1@city.ac.uk

Funding The authors have not declared a specific grant for this research from any funding agency in the public, commercial or not-for-profit sectors.

Competing interests None declared.

Patient consent for publication Not required.

Provenance and peer review Not commissioned; internally peer reviewed.

Data availability statement No data are available. There are no data in this interview. (c) Author(s) (or their employer(s)) 2020. No commercial re-use. See rights and permissions. Published by BMJ.

\section{D) Check for updates}

To cite: Khouli H, Nigam A. BMJ Leader 2020;4:162-164.

Received 4 May 2020

Accepted 7 May 2020

Published Online First 18 May 2020

BMJ Leader 2020;4:162-164.

doi:10.1136/leader-2020-000283

ORCID iD

Amit Nigam http://orcid.org/0000-0002-6772-9643 